\title{
REMODELLING OF THE HUMERUS AFTER SUPRACONDYLAR FRACTURES IN CHILDHOOD
}

\author{
C. (i. Attenborough, London, England
}

In the treatment of a supracondylar fracture of the humerus in childhood the aim should be a perfect anatomical reposition of the fragments, attained by closed manipulation. If for any reason it is found impossible to achieve this ideal, there are two alternatives: open reduction, or immobilisation in the unreduced position. Open reduction is widely favoured at the present time. It is a common experience, however, that anatomical reduction gained by operation is followed by varying degrees of stiffness of the elbow, often severe and permanent.

It is the object of this paper to report a number of cases treated by the second alternative. Here the unreduced position is accepted, provided the alignment is good. The elbow is immobilised in plaster until the fracture is united, and remodelling of the humerus is allowed to proceed. The restoration towards normal anatomy is rapid and in some cases remarkable, and it is contended that the functional results are often better than those of open reduction.

It should be emphasised at the outset that it is not the object here to advocate nonreduction of all supracondylar fractures of the humerus. This method has been used only in those cases in which, for various reasons, an anatomical reduction could not be obtained by manipulation. It is only in children that remodelling can be relied upon for any marked anatomical improvement. All the patients in the following cases were under the age of ten years at the time of injury. The upper age limit has not been determined, but the degree of remodelling becomes progressively less in adolescence and is very limited in adults.

\section{CASE REPORTS}

Case 1-Boy aged seven years. Admitted with a supracondylar fracture of the left humerus, with medial displacement. Four attempts at reduction failed to improve the position materially (Fig. 1), and it was therefore accepted. Plaster immobilisation was continued for five weeks,

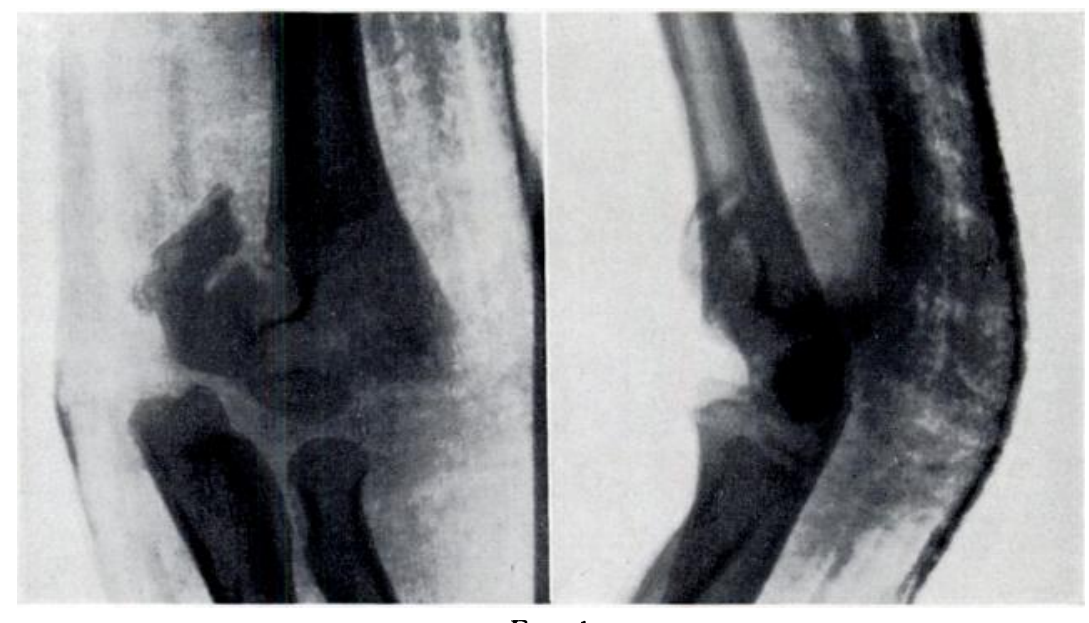

FIG. 1

Case 1-Position accepted after unsuccessful attempts at reduction.

after which radiographs showed marked new bone formation beneath the stripped periosteum on the medial and posterior aspects of the lower end of the humerus (Fig. 2). Six weeks later the range of movement was from 110 degrees to 180 degrees. A year later the range was from 75 degrees 
REMODELLING OF THE HCMERIS AFTER SLPRACONDYLAR FRACTLRES IN CHILDHOOD 387

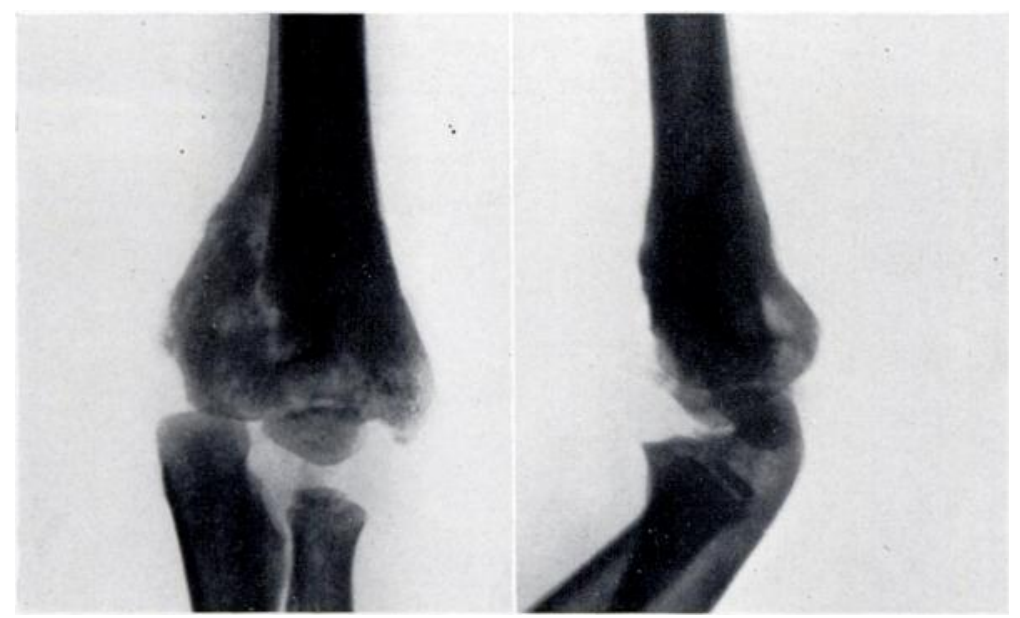

FIG. 2

Case 1-Five weeks later.

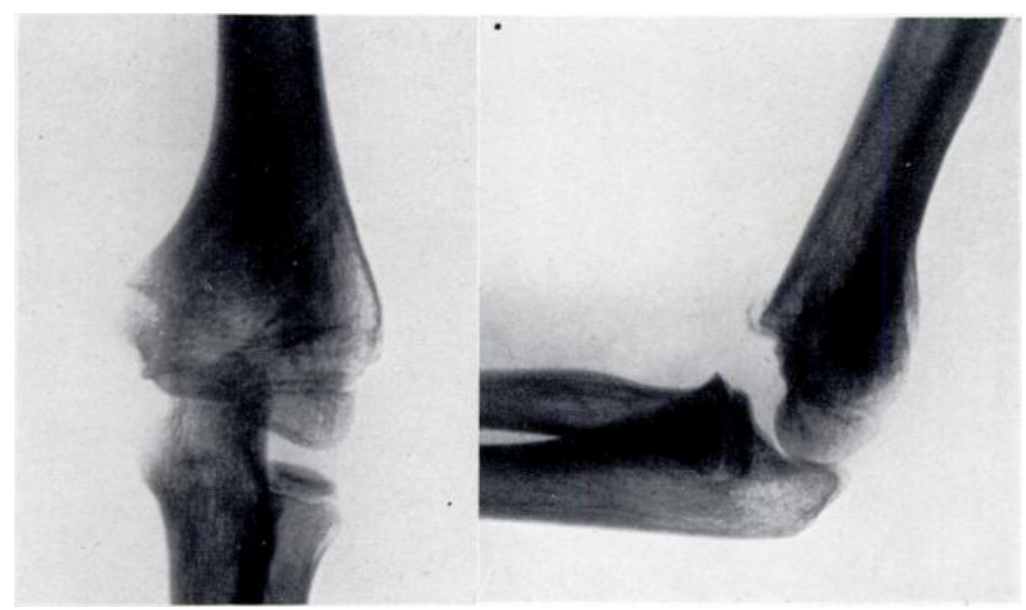

FIG. 3

Case 1--Two years after injury. Note marked remodelling.
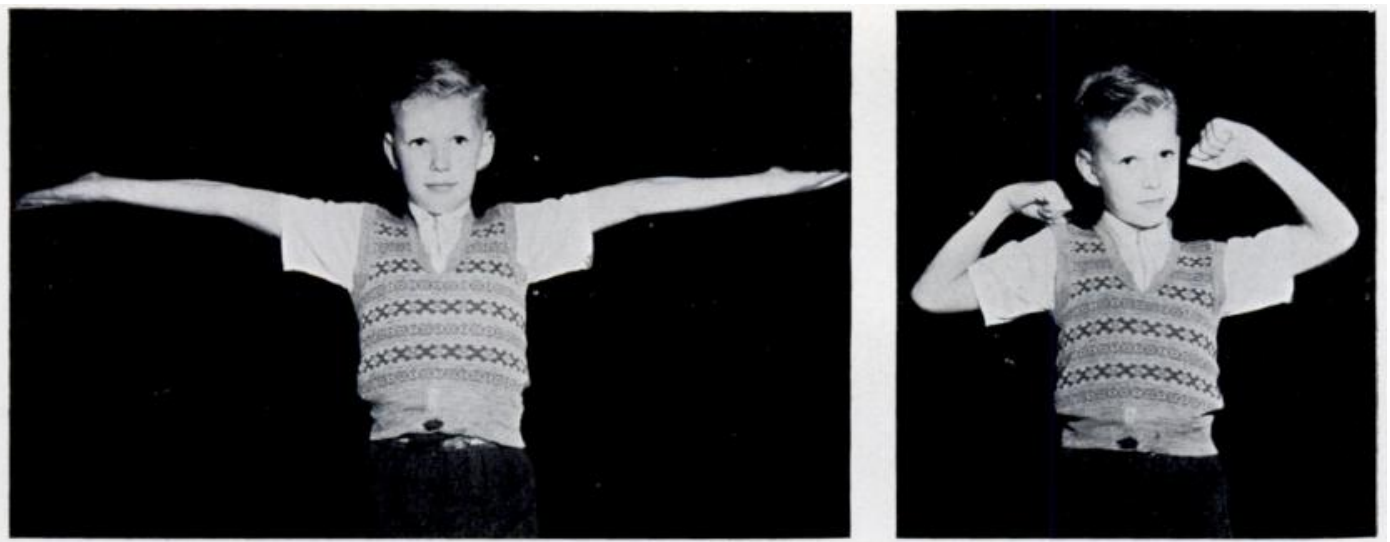

FIG. 4

Case 1-Showing range of elbow movement two and a quarter years after injury.

vol. 35 B, No. 3, AUgust 1953

$\mathrm{D}$ 
to 190 degrees ( 5 degrees hyperextension was present in the normal elbow). Two years after the injury the anterior spur, though still present, was smaller and was relatively higher up the shaft of the humerus as growth proceeded at the lower humeral epiphysis (Fig. 3). The lateral spur had been completely absorbed. Four months later the left elbow range was from 65 degrees to 190 ) degrees (Fig. 4) and there was slight cubitus varus.

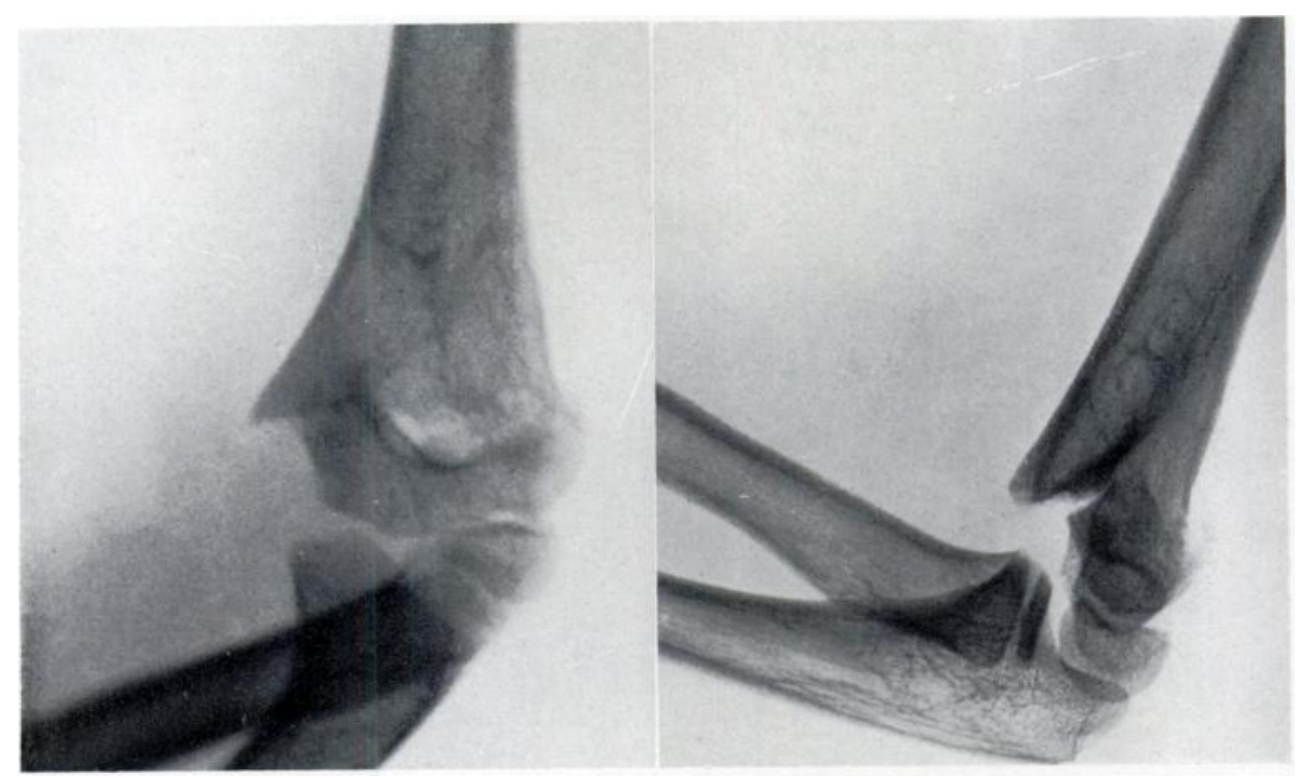

FIG. 5

Case 2--Initial radiograph.

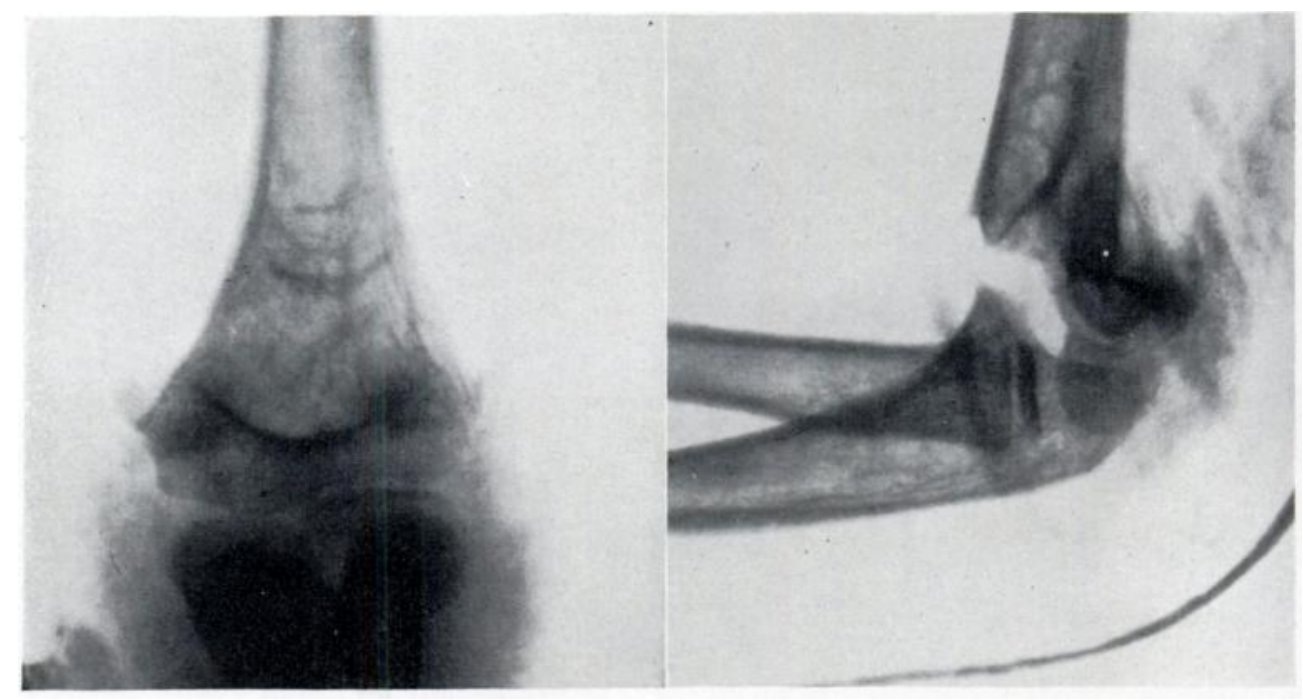

Fig. 6

Case 2- Position accepted after redisplacement of fragments.

Case 2 Boy aged nine years. Admitted with a supracondylar fracture of the left humerus (Fig. 5). Manipulation had failed to produce a satisfactory position. A good reduction was obtained three days later after a second manipulation. A plaster was applied with the elbow at a right angle. A few days later radiographs showed that the fragments had redisplaced (Fig. 6). Two further manipulations failed to improve the position and it was accepted. Radiographs thirteen days 


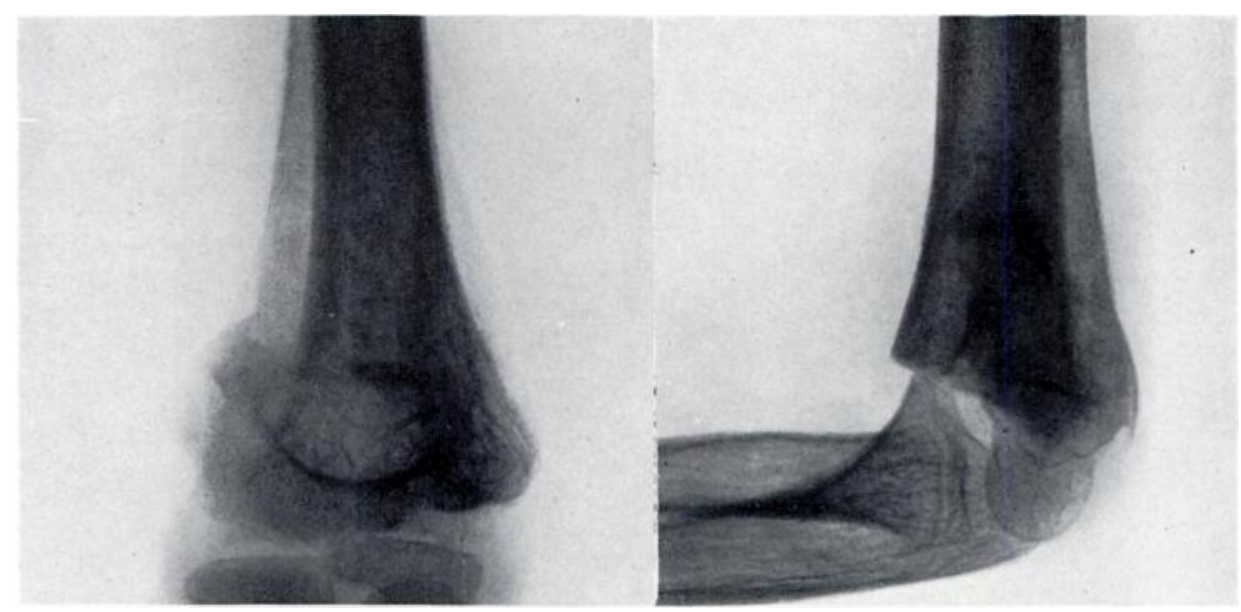

Fig. 7

Case 2-Remodelling of humerus seven weeks after injury.

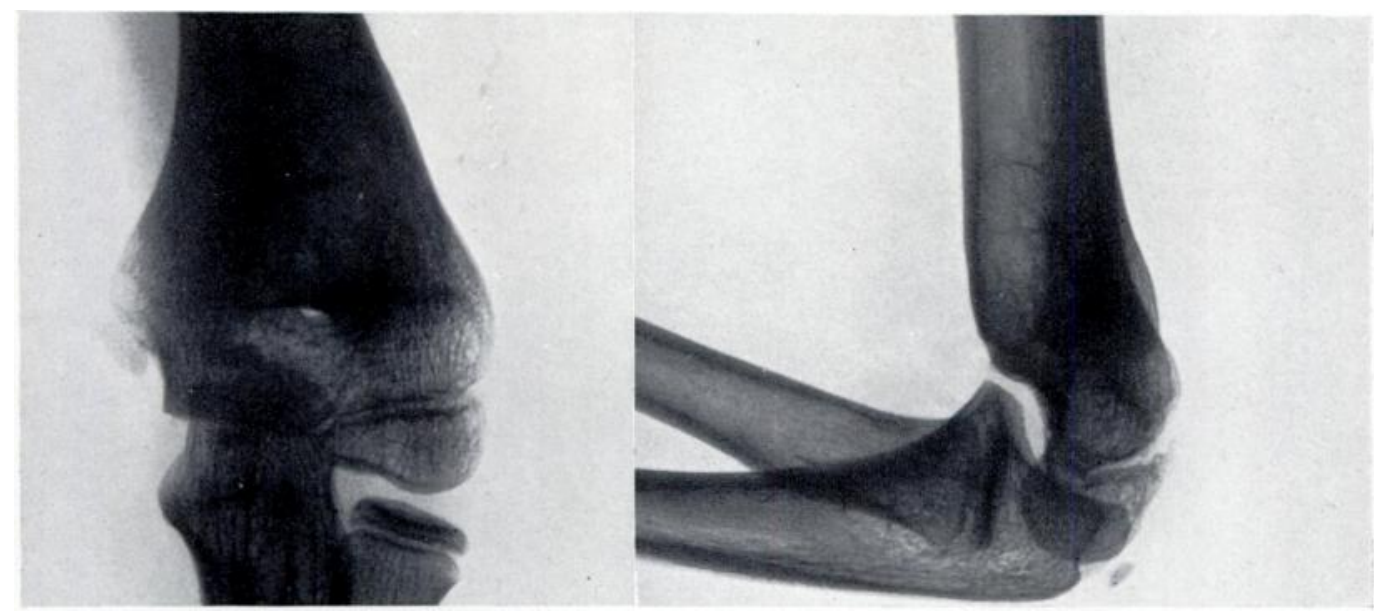

FIG. 8

Case 2 - Condition eighteen months after injury
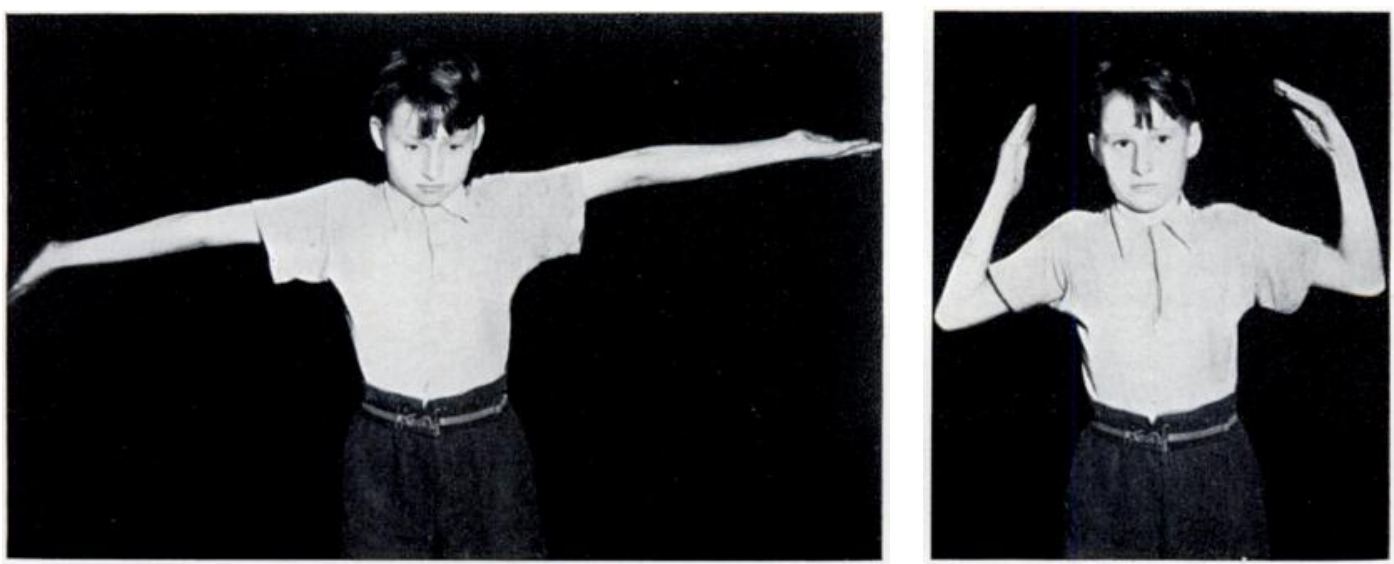

Fig. 9

Case 2-Showing range of elbow movement eighteen months after injury.

vol. 35 B, No. 3, AUgust 1953 
after injury already showed subperiosteal new bone. The plaster was removed after seven weeks and radiographs showed well marked remodelling (Fig. 7). One month later the elbow movement was from $\mathbf{8 5}$ degrees to $10(1)$ degrees. Ten months after the injury it was from 80 degrees to 180 degrees. A year and a half after the injury radiographs showed absorption of projecting spurs, with an increasing distance between the residual anterior spur and the elbow as growth progressed

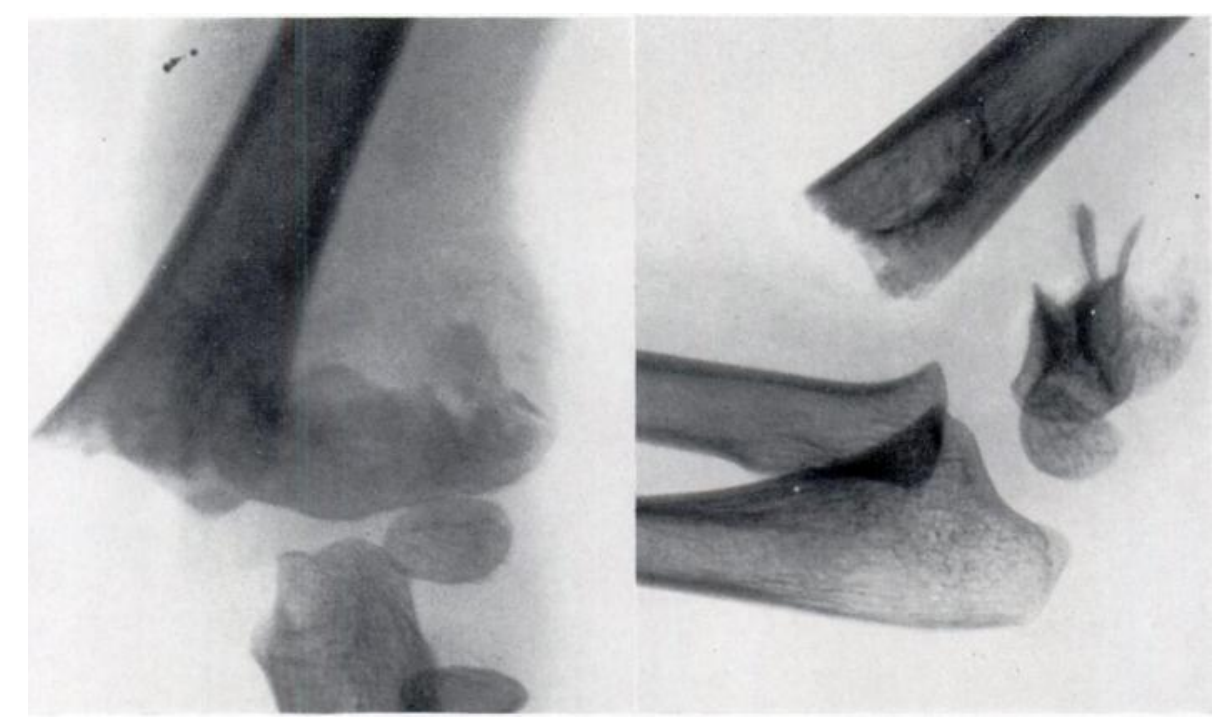

FIG. III

Case 3-Initial radiograph.

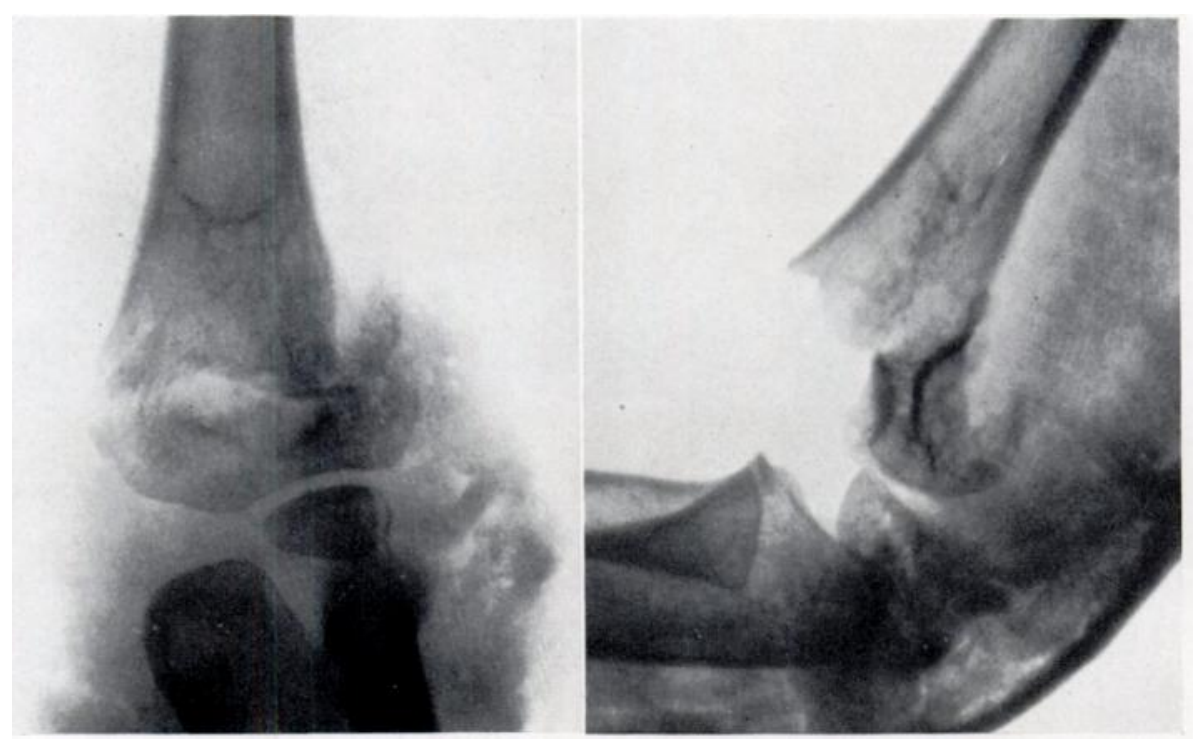

FIG. 11

Case 3 -P'osition accepted after unsuccessful attempts at reduction.

(Fig. 8). The elbow range was from 60 degrees to 180 degrees (Fig.9), and there was a cubitus varus of 15 degrees.

Case 3-Boy aged five years. Admitted with a grossly displaced supracondylar fracture of the left humerus (Fig. 10). Two attempts at reduction failed to overcome the posterior displacement, but the alignment was good and the position was accepted (Fig. 11). Immobilisation in a plaster 


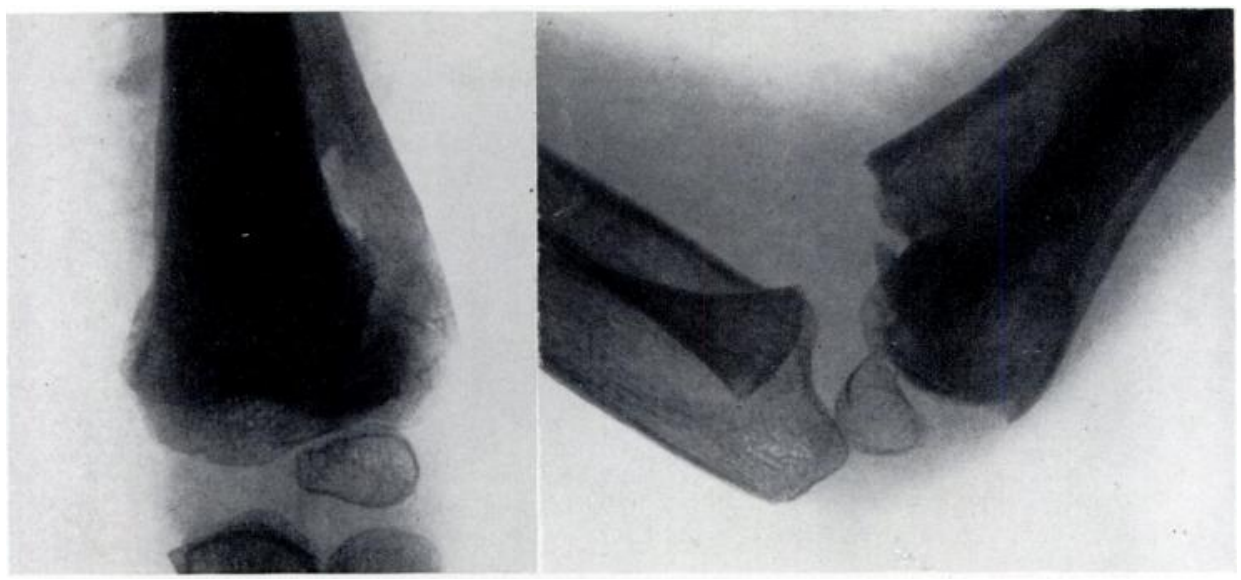

FIG. 12

Case 3-Remodelling of humerus eight weeks after injury:

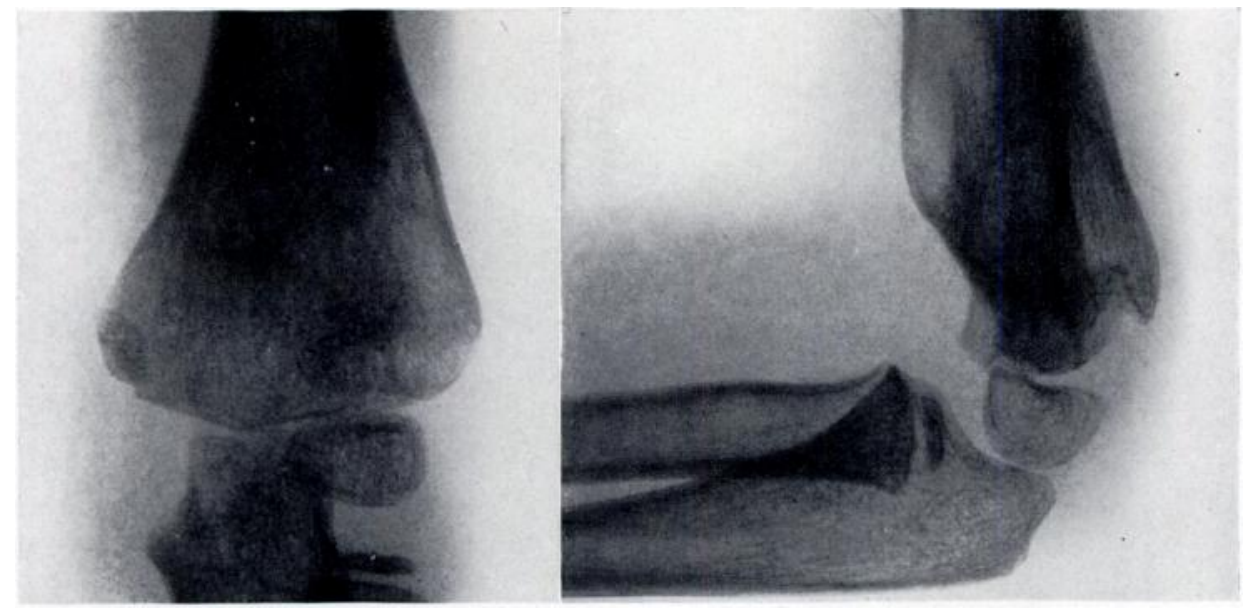

FIG. 13

Case 3-Condition one and a half years after injury.
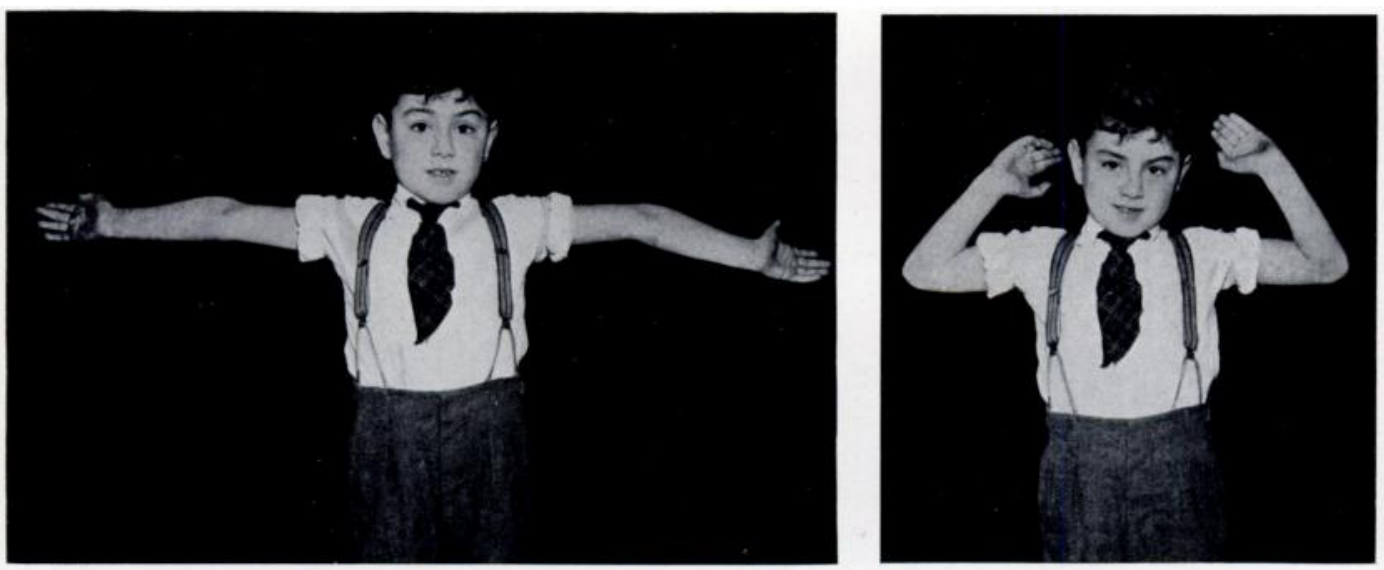

FIG. 14

Case 3-Showing range of elbow movement one and a half years after injury.

vol. $35 \mathrm{~B}$, No. 3 , AUG $\ddot{\mathrm{ST}} 1953$ 
cylinder with the elbow at a right angle was continued for eight weeks, after which radiographs showed marked remodelling (Fig. 12). One month later the range of elbow movement was from 90 degrees to 175 degrees. A year and a half after the injury radiographs showed considerable advancement of the remodelling process (Fig. 13). The elbow range was from 60 degrees to 190 degrees (10 degrees hyperextension, compared with 5 degrees in the right elbow) (Fig 14). There was cubitus varus of 5 degrees.

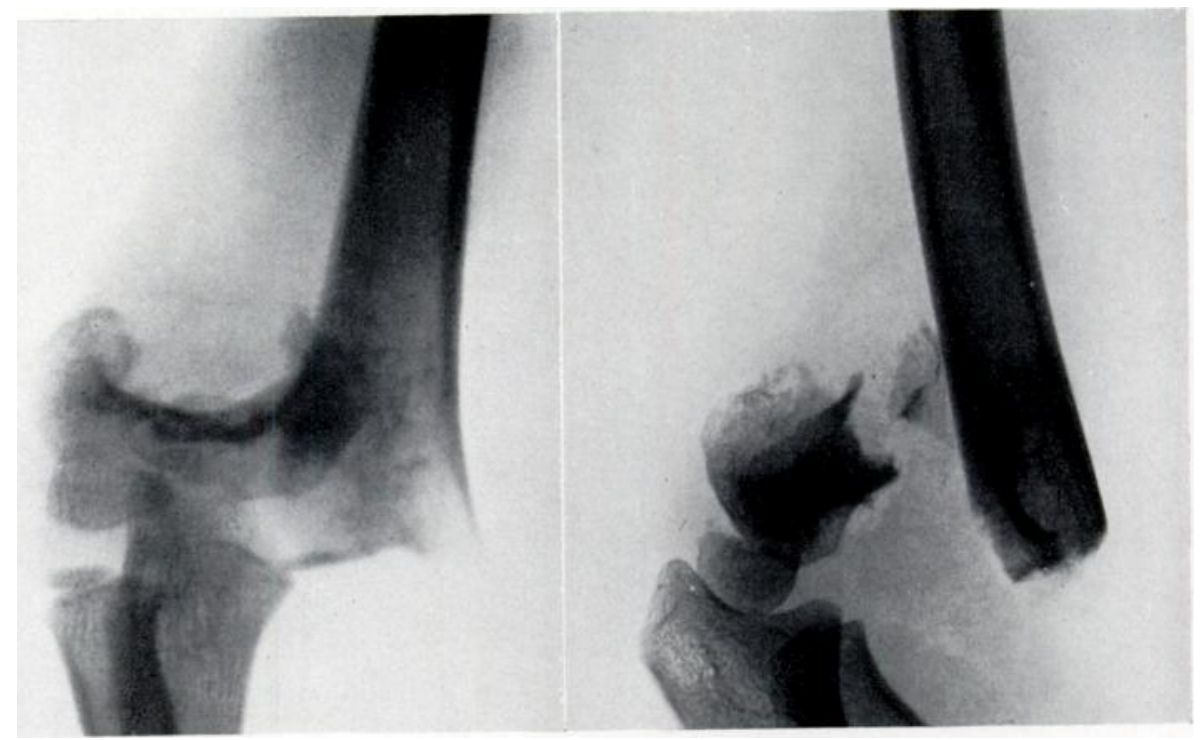

Fig. 15

Case 4-Initial radiograph.

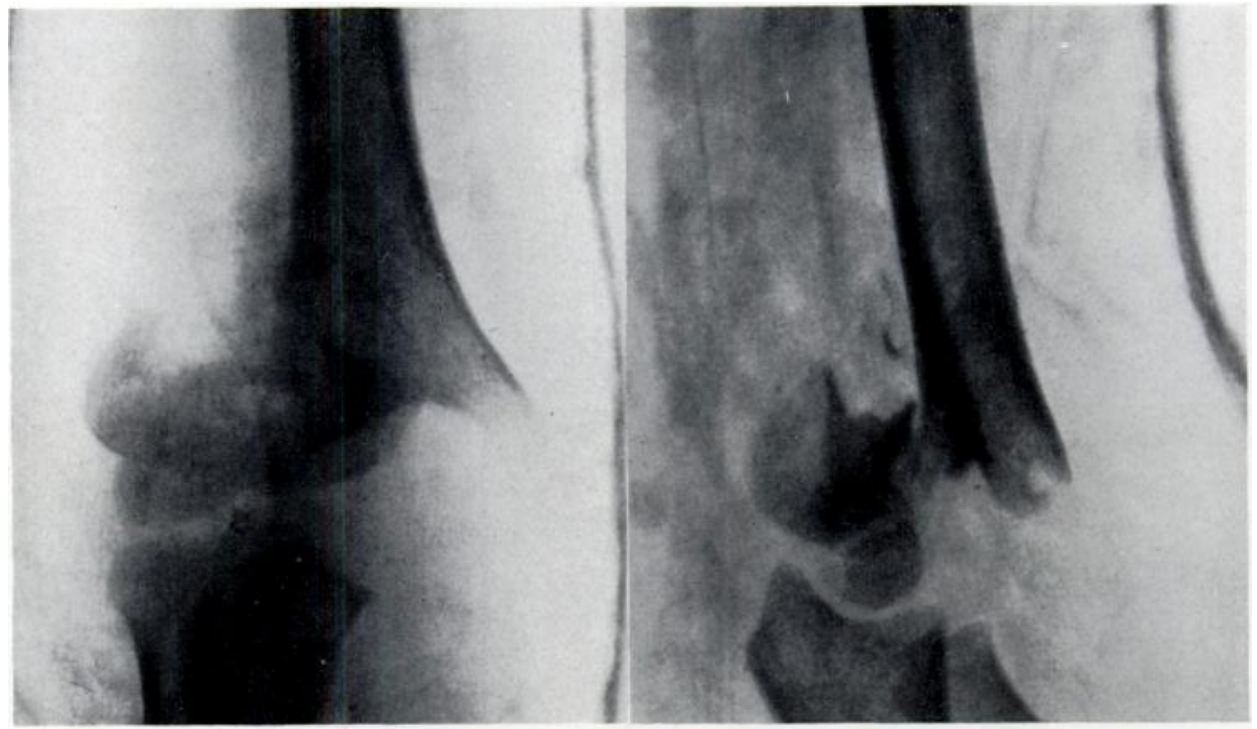

FIG. 16

Case 4-Position accepted after redisplacement of the fragments.

Case 4-Boy aged seven years. Admitted with a supracondylar fracture of the right humerus. There was gross displacement posteriorly and laterally, and an incomplete median nerve palsy (Fig. 15). Manipulation failed to reduce the fracture and was repeated three days later. This time a good position was obtained, but, because of the marked swelling, it was found necessary to immobilise the elbow in a considerable amount of extension. Radiographs four days later showed redisplacement of the fracture (Fig. 16). The position was accepted and immobilisation 
REMODELLING OF THE HUMERUS AFTER SLPRACONDYLAR FRACTURES IN CHILDHOOD 393

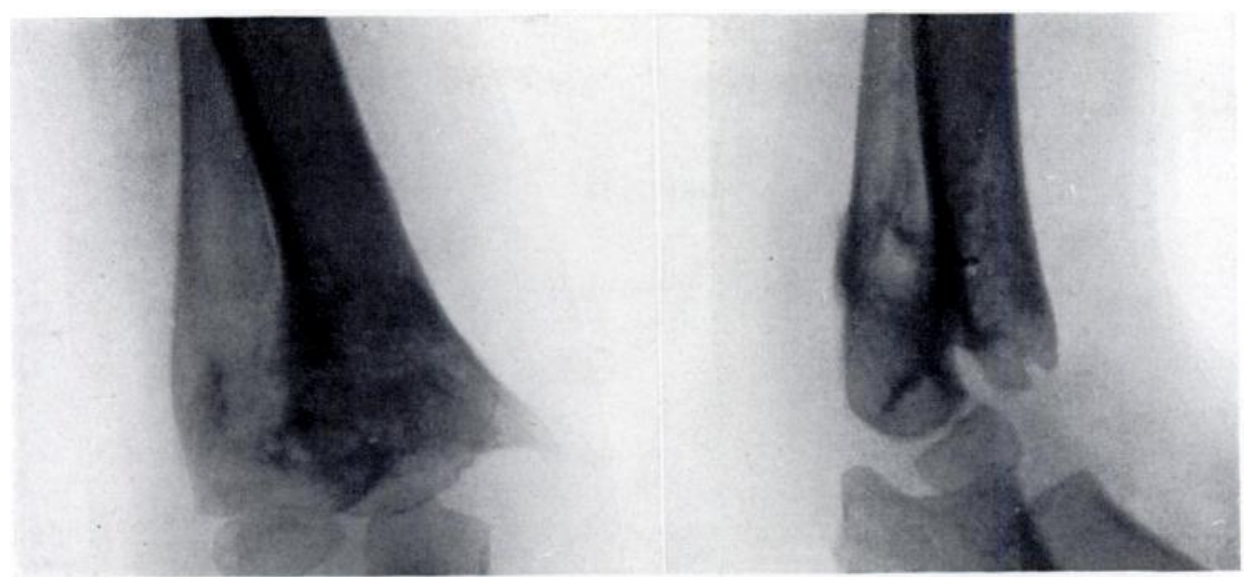

FIG. 17

Case 4-Remodelling five weeks after injury:

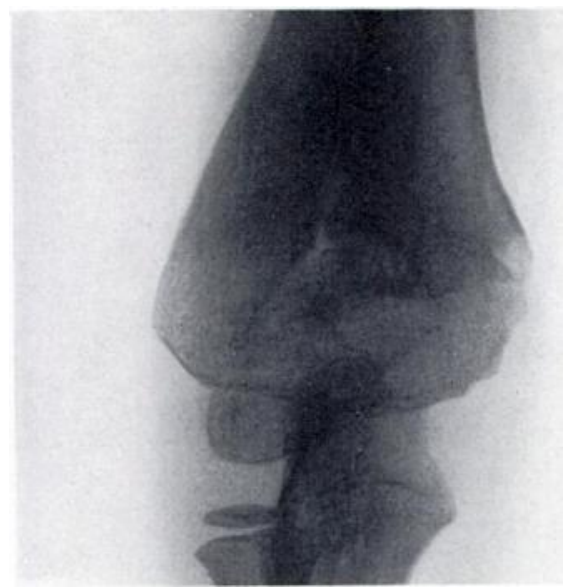

Fig. 1i

Case 4 -Condition seven months after injury.
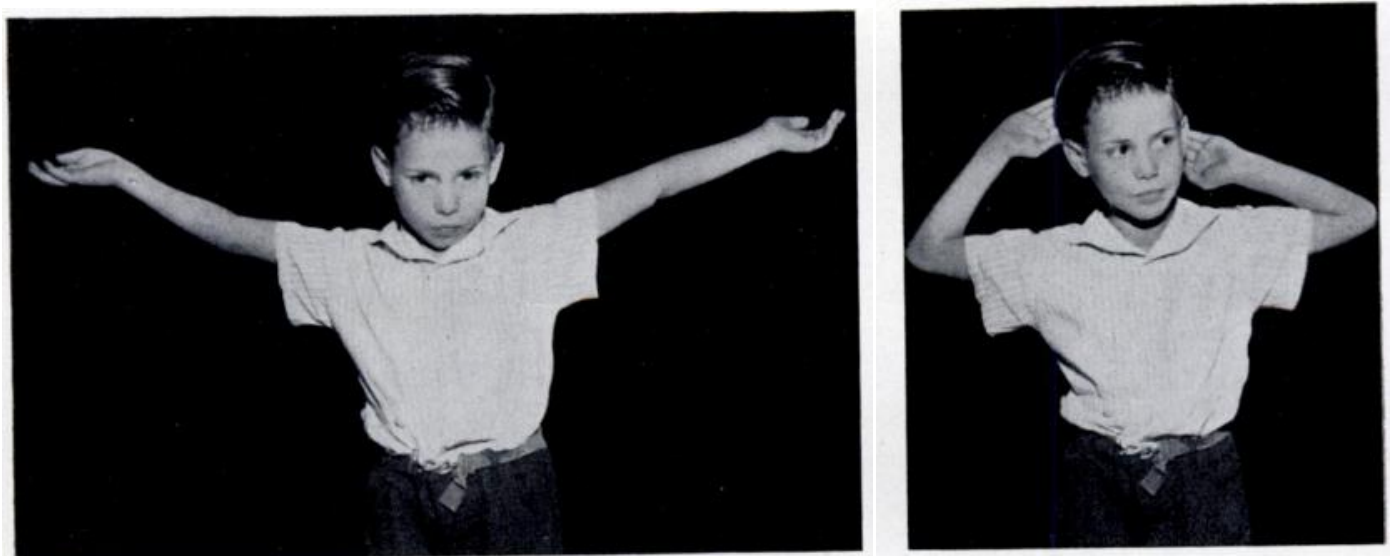

Fig. 19

Case 4-Showing range of elbow movement seven months after injury.

VOL. $35 \mathrm{~B}$, No. 3, AUgust 1953 
continued for five weeks. Radiographs then showed new bone formation beneath the stripped periosteum on the lateral and posterior aspects (Fig. 17). Five months later, further radiographs showed a remarkable degree of remodelling, with complete absorption of the medial spur, and a rapidly diminishing anterior projection (Fig. 18). The range of movement was from 45 degrees to 180 degrees (Fig. 19).

\section{DISCUSSION}

Supracondylar fractures of the humerus in childhood can be difficult injuries to treat. Few will deny that the standard method of treatment should be by closed manipulation and immobilisation in a plaster slab and collar-and-cuff sling. Later, when the swelling has subsided, a complete plaster cylinder may be used. The elbow should be in as much flexion as the swelling will allow, provided a strong radial pulse is retained. The optimum is about 45 degrees above the right angle, but it is frequently dangerous to flex the elbow to this extent, and a right-angled position, or even some degree of extension, may have to be accepted. If necessary, the manipulation may be repeated when the swelling has subsided (Watson-Jones 1943), but this should not be left later than five to seven days. The fracture rapidly becomes "sticky" and subperiosteal new bone formation may be seen radiographically within ten days or even earlier.

The difficulty arises when a satisfactory position cannot be obtained by manipulation; when redisplacement occurs despite repeated manipulations; or, rarely, when the fracture is first seen after an interval of several days since injury, still with its original displacement. The recent literature on the subject stresses the methods of operative treatment. Thus Swenson (1948) reported a series of patients treated by closed reduction and fixation by Kirschner wires inserted " blindly." Donchess (1949) advocated a posterior midline approach to the fracture site, and, after reduction under vision, fixation with Kirschner wires. Both these authors reported good final functional results. Sandegard (1943) was more guarded. While advocating operation for the "stubborn" cases, he stated that alteration of the carrying angle might occur in consequence, and that limitation of movement was common after operative reduction.

It has been a frequent finding that although an anatomical reduction may be obtained by operation a considerable measure of elbow stiffness often results, especially if metal or other foreign bodies are used in close proximity to the joint.

The alternative method of treatment is not new. Hey Groves (1916) commented upon the degree of remoulding which will take place in children. It seems, however, that this is in danger of being forgotten in an age of many operative procedures.

In the conservative treatment used in the cases reported here the fragments were left in the best position obtained by manipulation and the elbow was immobilised at a right angle in a plaster cylinder. In the earlier cases the immobilisation was continued for five weeks. In the light of experience, this time was extended to between six and eight weeks. Premature removal of the plaster seemed to result in a painful elbow, with marked spasm and subsequent slow progress. The longer period of immobilisation has been followed by a more rapid return of function.

Although quite severe posterior and lateral displacement may be accepted, the alignment must be good. Rotational deformity is seemingly not corrected by remodelling, except perhaps in infants. In two cases of this series slight backward tilting has resulted in hyperextension of the elbow, with more marked limitation of flexion than would otherwise be present. In three cases there is some cubitus varus, though this may have been caused partly by disturbance of growth at the lower humeral epiphysial line. In all cases the displacement, as opposed to rotation, of the distal fragment, has been smoothed off by the process of remodelling. Subperiosteal new bone formation is well marked, and projecting spurs are absorbed. The medial or lateral spur is absorbed particularly rapidly and the anterior spur more slowly. The residual anterior projection tends to become relatively higher

THE JOURNAL OF BONE AND JOINT SURGERY 
up the shaft of the humerus as growth proceeds, and causes less of a block to flexion of the elbow.

All these patients regained a full range of extension of the elbow within a few months of removal of the plaster. Flexion was regained rather more slowly and has continued to improve for a long time. In every case, the range of flexion is still increasing as the anterior spur diminishes.

\section{SUMMARY}

Four cases are shown to illustrate remodelling of the lower end of the humerus after supracondylar fractures with displacement in childhood. Remodelling is rapid and will restore almost normal anatomy and good function even with severely displaced fractures. The results are much better than in many cases treated by open reduction.

I wish to express my sincere thanks to Mr Cecil Flemming and Mr J. R. Armstrong for their guidance and encouragement, and for permission to publish these cases which were treated under their care. I wish also to thank Sir Reginald Watson-Jones for his helpful advice. For the clinical photography, my thanks are due to Mr R. F. Ruddick of the Photographic Department of the London Hospital.

\section{REFERENCES}

Donchess, J. C. (1949): Treatment of Supracondylar Fracture of the Humerus. Journal of the Indiana State Medical Association, 42, 217.

Groves, E. W. Hey (1916): On Modern Methods of Treating Fractures. Bristol: John Wright \& Sons Ltd. SANDEgard, E. (1943): Fractures of the Lower End of the Humerus in Childhood-Treatment and End Results. Acta Chirurgica Scandinavica, 89, 1.

Swenson, A. L. (1948): The Treatment of Supracondylar Fractures of the Humerus by Kirschner-Wire Transfixion. Journal of Bone and Joint Surgery, 30-A, 993.

Watson-Jones, R. (1943) : Fractures and Joint Injuries. Third edition. Edinburgh: E. \& S. Livingstone Ltd. 